\title{
Interactions of Policies for Renewable Energy and Climate
}

International Energy Agency 



\section{Interactions of Policies for Renewable Energy and Climate}

The views expressed in this working paper are those of the author and do not necessarily reflect the views or policy of the International Energy Agency (IEA) Secretariat or of its individual member countries. This paper is a work in progress, designed to elicit comments and further debate; thus, comments are welcome, directed to the author at: cedric.philibert@iea.org

International Energy Agency

Cédric Philibert 
The International Energy Agency (IEA), an autonomous agency, was established in November 1974. Its primary mandate was - and is - two-fold: to promote energy security amongst its member countries through collective response to physical disruptions in oil supply, and provide authoritative research and analysis on ways to ensure reliable, affordable and clean energy for its 28 member countries and beyond. The IEA carries out a comprehensive programme of energy co-operation among its member countries, each of which is obliged to hold oil stocks equivalent to 90 days of its net imports. The Agency's aims include the following objectives:

- Secure member countries' access to reliable and ample supplies of all forms of energy; in particular, through maintaining effective emergency response capabilities in case of oil supply disruptions.

- Promote sustainable energy policies that spur economic growth and environmental protection in a global context - particularly in terms of reducing greenhouse-gas emissions that contribute to climate change.

- Improve transparency of international markets through collection and analysis of energy data.

- Support global collaboration on energy technology to secure future energy supplies and mitigate their environmental impact, including through improved energy

efficiency and development and deployment of low-carbon technologies.

Find solutions to global energy challenges through engagement and dialogue with non-member countries, industry, international organisations and other stakeholders.

IEA member countries:

\section{Austria}

Belgium

Canada

Czech Republic

\section{Denmark}

Finland

France

Germany

Greece

Hungary

Ireland

Italy

Japan

Korea (Republic of)

Luxembourg

Netherlands

New Zealand

Norway

Poland

Portugal

(c) OECD/IEA, 2011

\section{International Energy Agency}

9 rue de la Fédération

75739 Paris Cedex 15, France

www.iea.org

Please note that this publication

is subject to specific restrictions

that limit its use and distribution.

The terms and conditions are available

online at www.iea.org/about/copyright.asp

Slovak Republic

Spain

Sweden

Switzerland

Turkey

United Kingdom

United States

The European Commission

also participates in

the work of the IEA. 


\section{Table of Contents}

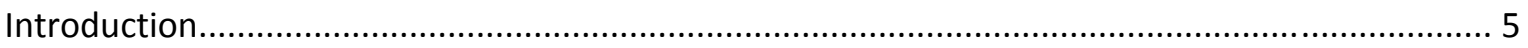

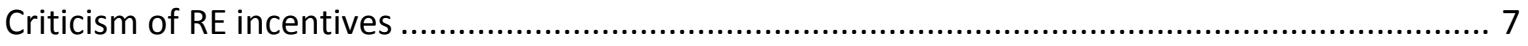

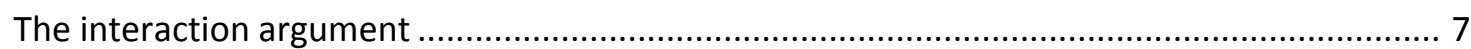

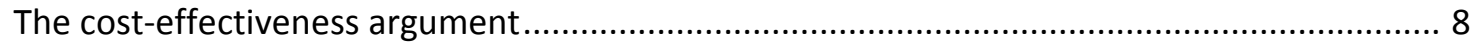

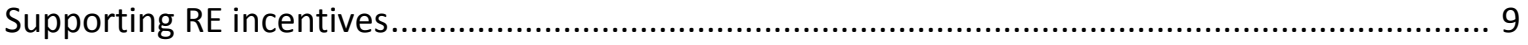

Other drivers of RE deployment policies.................................................................. 9

The need for a longer-term perspective ................................................................. 10

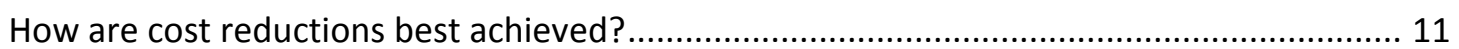

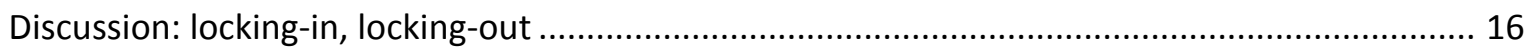

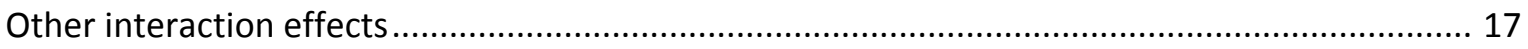

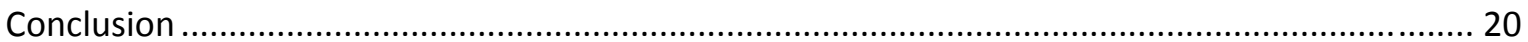

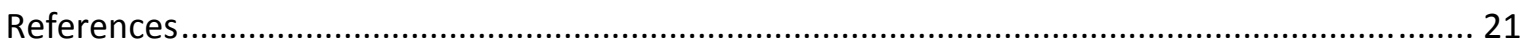

List of figures

Figure 1: Electricity generation by sources in 2007, 2030 and 2050 under Baseline, BLUE Map, BLUE High Nuclear and BLUE High Ren scenarios. ............................................. 11

Figure 2: Photovoltaic learning curve 1976-92: linear and log-log representations .................... 13

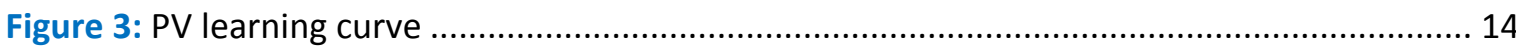

Figure 4: Corporate and public PV R\&D expenses ......................................................... 15

Figure 5: Average wholesale electricity prices and renewable support cost

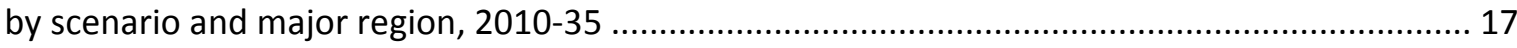

Figure 6: How wind power influences the power spot price at different times of the day........... 18

Figure 7: Merit order and electricity price increase with $\mathrm{CO}_{2}$ price ..................................... 19

\section{List of boxes}

Box 1: Behind the learning curve 



\section{Introduction}

More than 70 governments around the world, and among them all IEA member countries, have put in place targets and policies to support the deployment of renewable energy (RE) technologies. In doing so, they pursue a great variety of objectives, including improving energy security and access to energy services; reducing dependence on energy-exporting countries; environmental protection; climate-change mitigation; provision of employment; and strengthening the competitive edge of their domestic industry.

Meanwhile, the negotiations in the framework of the United Nations Framework Convention on Climate Change (UNFCCC) led, in 2005, to the entry into force, for ratifying countries, of the Kyoto Protocol. The Protocol assigns binding targets relative to their emissions of carbon dioxide and other greenhouse gases (GHG), to countries listed in its Annex I (industrialised countries). More recently, the international community formally agreed (Cancun, Mexico, December 2010) to limit global warming to $2^{\circ} \mathrm{C}$ from pre-industrial level, and to consider in only a few years' time possibly strengthening this objective to limit global warming to $1.5^{\circ} \mathrm{C}$.

Renewable energy (RE) technologies will play a very important role in reducing GHG emissions; but they alone would not suffice to keep climate change manageable. Energy efficiency improvements, in particular, have been identified as the largest potential for energy-related $\mathrm{CO}_{2}$ emission cuts. The IEA also includes greater nuclear power deployment, as well as carbon capture and storage (CCS) technologies in its climate-friendly scenarios. The question is often raised: is it necessary or even useful to have two distinct types of policies and objectives, one series for promoting RE technologies, and another one directly addressing GHG emissions?

Some economists argue that RE incentives are counterproductive when they interfere with a capand-trade policy such as the European Union's Emissions Trading System (EU ETS). By lowering the price of carbon, policies that support RE appear to favour the most polluting forms of fossil fuels. More importantly perhaps, it is argued that $\mathrm{CO}_{2}$ prices can single-handedly drive the optimal deployment of low-carbon technologies, including renewables. According to these scholars, specific renewable policies would not only be redundant but also raise the cost of climate change mitigation.

Proponents of RE policies usually respond by stating that RE policies have multiple objectives, as mentioned above. While essentially correct, this argument may not by itself suffice, as its validity is somewhat mitigated by the observation that other options to reduce $\mathrm{CO}_{2}$ emissions could also, at least in part, satisfy these same other objectives.

Another consideration bears a greater weight - that the current investments in RE technologies are essential to quickly reducing their cost and to make a wide portfolio of RE technologies affordable and competitive on a large scale beyond their current niche markets. IEA scenarios show that RE technologies will have to play a pivotal role in this century if climate change is to be mitigated. If the overall costs of mitigation during the next decades are considered, the economic assessment might differ substantially. Immediate $\mathrm{CO}_{2}$ reductions driven by the early deployment of RE may cost more than other options today, but will reduce the costs of mitigating climate change in the future. The risk that some mitigation options may fall short should motivate policy makers to consider higher-cost options that effectively provide insurance against catastrophic climate change.

This paper aims to critically review the arguments about the interactions between $\mathrm{RE}$ and $\mathrm{CO}_{2}$ policy instruments. It shows that developing new renewable resources (e.g. wind, solar and others) from a very narrow basis today allows learning that will unlock their climate-change mitigation potential. By contrast, the associated minor change in the rate of switching fuel from coal to gas does not lock the energy sector into more polluting technologies. 
The paper concludes that incentives for the deployment of not-yet competitive forms of RE are legitimate even if $\mathrm{CO}_{2}$ is appropriately priced, provided policy instruments are well designed and related costs kept under control. Closer examination of possible interactions between $\mathrm{RE}$ and $\mathrm{CO}_{2}$ policy instruments also reveals other little-noticed aspects, relating to how both policies transfer wealth from utilities to (deregulated) customers or vice versa. This opens a whole set of issues Page I 6 relating to the long-term financing of electricity systems, which could be subject to future research work. 


\section{Criticism of RE incentives}

\section{The interaction argument}

In a thought-provoking paper, Böhringer and Rosendahl (2009) claim that "Green Serves the Dirtiest", through a so-called "interaction" effect. RE support policies (quotas in their model tradable green certificate or TGC more generally) do, as a first-order effect, reduce the profitability of "black power" (i.e. from fossil fuels), and thus reduce output from all fossil-fuel producers. However, in a country or group of countries such as the European Union, where an emissions trading system (ETS) covers the $\mathrm{CO}_{2}$ emissions from electricity production, emission reductions resulting from the deployment of renewables lead to reduced pricing of emissions. In essence, they reduce the advantage given to efficient combined cycle gas turbines over coal plants. Emissions are not reduced further due to the RE incentives, as long as the quantitative cap is set once and maintained, insensitive to $\mathrm{CO}_{2}$ prices.

Meanwhile, policies that successfully increase the share of renewable, non-carbon emitting electricity production tend to reduce overall emissions and displace electricity production from fossil fuels. In doing so, they relatively reduce the $\mathrm{CO}_{2}$ price, thereby diminishing the advantage given by the instauration of the ETS to the lower carbon-emitting technologies among electricity production technologies from fossil fuels. This benefits the more emission-intensive technologies.

There is at present nothing to "force" the fossil fuel producers to increase their output and keep total emissions constant. They might do so for economic reasons, but they might as well save allowances and sell them to other entities whose emissions are covered by the ETS - for example in other industrial sectors. In any case, the total emissions are likely to be the same regardless of whether a policy to specifically promote renewable electricity production is in place, as long as the quantitative cap is set, insensitive to $\mathrm{CO}_{2}$ prices. ${ }^{1}$ The ETS creates an absolute cap: unless the unabated emission trends were to put emissions below the cap and the carbon price were to fall to zero, emissions would be exactly on target, supposing full compliance. Carbon price with null value may result from a not-too-demanding cap on emissions, a lower-than-expected economic growth, a very stringent renewable energy target, or any combination of these.

The interaction of both policies reduces the disadvantage that ETS alone would create for coal plants relative to gas plants. One must insist that Böhringer and Rosendahl's result is only a second-order effect, for this might have been misread by some reviewers. For example, Fischer and Preonas (2010), reviewing Böhringer and Rosendahl's paper, write that "while overall fossil fuel production falls as a result of combined ETS and TGC quotas, the dirtiest producers actually increase output to keep total $\mathrm{CO}_{2}$ emissions at the binding ETS ceiling." The reader might thus believe that this is an absolute increase over the baseline, i.e. the situation where no policy of any kind would be enacted.

The model presented in Börhinger and Rosendhal actually reveals something quite different. When the emission constraint is imposed, power production by lignite power (the "dirtiest technology") decreases by $41 \%$ if no additional green quota is in place. When a green quota is introduced at $23 \%$ of total electricity, output from lignite power plants also decreases, but by only $31 \%$. The "benefit for the dirtiest" is not absolute, but clearly relative - an increase of $17 \%$ over the scenario with the ETS alone. Therefore, potential investors in coal plants are still confronted with a negative outlook.

\footnotetext{
${ }^{1}$ Note that if independent power producers (IPP) too small to be covered by the ETS turn to RE technologies, total $\mathrm{CO}_{2}$ emissions will be reduced. But if, as is often the case with wind or solar, new IPP enter the market with RE electricity, although this reduces the production from ETS-covered producers, the overall emissions will stay on target, i.e. their level is not affected by the RE policy.
} 


\section{The cost-effectiveness argument}

Many believe that the overlapping of $\mathrm{CO}_{2}$ and RE policy instruments increases the costs of achieving the $\mathrm{CO}_{2}$ objective. This argument follows a strong logic: the more expensive mitigation achieved through RE displaces reductions that the ETS would achieve at a lower cost. In cases

Page $\mid 8$ where RE would be driven by the $\mathrm{CO}_{2}$ price alone and RE incentives were to persist, the additional support only creates windfall profits.

The exact extent of the additional cost of RE support in achieving a given $\mathrm{CO}_{2}$ objective is difficult to evaluate. It depends on the cost of the promoted RE sources and on the amount of $\mathrm{CO}_{2}$ they avoid, and on the cost of avoiding same quantities through other measures that would have been mobilised, had renewables not been promoted. Electricity generation from renewables is particularly challenging: it requires an assessment of the $\mathrm{CO}_{2}$ content of the $\mathrm{kWh}$ they displace, which depends on the merit order (i.e. the last production capacity required to fulfil the demand at every moment). These elements typically differ from one country to another. This difficulty, however, does not make the point any less valid. ${ }^{2}$

\footnotetext{
${ }^{2}$ A fuller investigation of the short-term effects of these interactions would necessitate assessing the macro-economic effects of $\mathrm{CO}_{2}$ prices and changes in electricity prices. If RE deployment were required to achieve the short-term $\mathrm{CO}_{2}$ objectives (i.e. if no cheaper options were left out), having a specific RE incentive could help keep the $\mathrm{CO}_{2}$ and electricity prices lower, and their macro-economic effect less important. As the modelling by Böhringen and Rosendhal suggests, this is probably not the case today. But if their short-term assessment holds in the current context, it may not always hold.
} 


\section{Supporting RE incentives}

Various arguments can be made in response to the criticism of specific RE incentives when a broader $\mathrm{CO}_{2}$ policy is in place. This paper will consider the following:

1. Climate change mitigation is only one among many motives behind the promotion of renewables.

2. Climate change is a long-term issue. It might be important to implement higher cost options together with lower cost options, if the deployment of the former has the potential to reduce the longer-term costs of mitigation.

\section{Other drivers of RE deployment policies}

The support to renewables may have various drivers other than climate-change mitigation. These include 1) a contribution to increased energy security, reduced dependence from imported fossil fuels; 2) hedging against price volatility and long-term price increase of fossil fuels; 3) a contribution to the reduction of other pollutants and related risks arising from the use of other energy sources; 4) and a willingness to develop local employment, sometimes reinforced by a perception of the first mover's advantage.

While a unique policy instrument might work well when one objective is pursued, it is more likely that several objectives pursued together will require several policy instruments. When it comes to overlapping $\mathrm{CO}_{2}$ and RE policies, the additional cost imposed on the achievement of the $\mathrm{CO}_{2}$ target by the RE policy instrument might be simply considered the cost of reaching the other objectives pursued by this policy instrument.

These arguments are valid. Renewable technology deployment offers many benefits beyond its contribution to climate change mitigation, which need to be assessed and valued. However, the benefits may fall short in justifying the extra cost. Indeed, as will be shown, the energy options displaced by RE technologies would have also provided, at least in part, similar benefits.

With respect to $\mathrm{CO}_{2}$ emissions from fossil fuel combustion, possible emission reductions all belong to energy efficiency improvements, fuel switching to fuels with lower carbon content (usually from coal to natural gas in electricity production), nuclear or renewable, or carbon capture and storage. It is important to consider how these options fare relative to the other objectives possibly attributed to the policies supporting RE deployment.

Energy efficiency improvements contribute as much or perhaps more than RE to all the objectives assigned to RE policies. They reduce other pollution, increase energy security and often create local jobs (e.g. for home insulation).

Fuel switching may or may not contribute to increased energy security, depending on the resources of the country considered, and its relationships to exporting countries. It usually reduces other pollution along with $\mathrm{CO}_{2}$ emissions, for burning natural gas usually entails lower NOx, SOx, heavy metals and particulate emissions than burning coal.

Carbon capture and storage increases fuel consumption, and thus does not provide any hedge against price volatility and long-term price increase. It may, nevertheless, be considered to increase energy security in a carbon-constrained world for countries with coal resources (or even without, considering a possible diversification in fuels and providers). It captures and stores most atmospheric pollutants as well as $\mathrm{CO}_{2}$.

Nuclear power does not emit $\mathrm{CO}_{2}$ and the other pollutants generally associated with fossil fuel burning. Although nuclear raw fuels must often be imported, their share in the overall cost is much smaller than in the case of fossil fuels. In addition, diversifying fuels and broadening the portfolio of providers reduces energy security risks. 
Another aspect often overlooked in assessing policies with multiple objectives is that other means can be employed to achieve each objective individually. For example, while it is legitimate to account for the reduction of particulate, SOx or NOx emissions when renewable energy substitutes for some fossil fuel burning, one must also consider other possibilities (and associated costs) to reduce the same emissions. This could be achieved through cleaning the fuel, using low-NOx burners or end-of-pipe devices (such as filters, scrubbers, flue-gas desulphurisation and others).

As a result, the multiplicity of objectives or the existence of other benefits may fall short of fully justifying policy instruments specifically supporting the deployment of RE technologies particularly if the analysis remains focused on short-term effects and these instruments displace energy efficiency improvements.

\section{The need for a longer-term perspective}

The interactions between $\mathrm{RE}$ and $\mathrm{CO}_{2}$ policy instruments are likely to increase the cost of achieving the $\mathrm{CO}_{2}$ target set for the relatively short term. However, the requirement for climatechange mitigation extends far beyond the relatively short-term perspective in which $\mathrm{CO}_{2}$ targets were set - at best, 15 years in the case of the Kyoto Protocol, considering the time lag from its adoption at the end of 1997 and the end of its first commitment period at the end of 2012.

Indeed climate change is a very long-term issue. The Fourth Assessment Report of the Intergovernmental Panel on Climate Change has shown that to keep the global temperature within the range of $2^{\circ} \mathrm{C}$ to $2.4^{\circ} \mathrm{C}$ above the pre-industrial temperature at equilibrium, using the 'best estimate' of climate sensitivity, would require a reduction in global $\mathrm{CO}_{2}$ emissions in 2050 of $-50 \%$ to $-85 \%$ of 2000 emissions. It further offers emissions ranges for categories of stabilisation scenarios from 2000 to 2100 (IPCC, 2007). Mitigation efforts will need to extend over this entire century and maybe beyond.

It is widely acknowledged that these considerable emission reductions will require a broad portfolio of mitigation options. The IEA World Energy Outlook 2010 (WEO 2010), for example, suggests that by 2035 energy efficiency improvements above those adopted in the Reference Scenario would provide $47 \%$ of the $\mathrm{CO}_{2}$ emission reductions in the 450 Scenario; additional emission reductions would come from broader use of renewable and biofuels (24\%), CCS (19\%), and additional nuclear power plants (8\%0 (IEA, 2010a).

The IEA Energy Technology Perspectives 2010 (ETP 2010) BLUE Map Scenario charts a path to a reduction in global energy-related $\mathrm{CO}_{2}$ emissions by $50 \%$ from 2005 levels at the lowest possible overall cost (IEA, 2010b). It shows that by 2050 renewable energy sources will provide about half of global electricity (Figure 1 ).

The High Renewable variant of the BLUE Map Scenario suggests that, if nuclear, CCS or energy efficiency improvements cannot deliver all that they promise, or if deeper cuts in $\mathrm{CO}_{2}$ emissions are warranted, RE sources could provide up to $75 \%$ of global electricity by 2050 . The increase in the cost of electricity would be about $10 \%$.

The necessary large-scale deployment of low-carbon energy technologies in the coming decades will result from significant cost reductions of the energy they deliver. The costs of deploying CCS technologies or concentrating solar electricity are divided by four from current levels; the cost of photovoltaic (PV) modules by six; the cost of fuel cell for vehicles by an even greater figure. The costs of associated $\mathrm{CO}_{2}$ emissions reductions with respect to the baseline scenario can be reduced even more. For example, when RE technologies become fully competitive, the marginal cost of associated emission reductions falls to zero. 
Figure 1: Electricity generation by sources in 2007, 2030 and 2050 under Baseline, BLUE Map, BLUE High Nuclear and BLUE High Ren scenarios.

Source: IEA, 2010b.

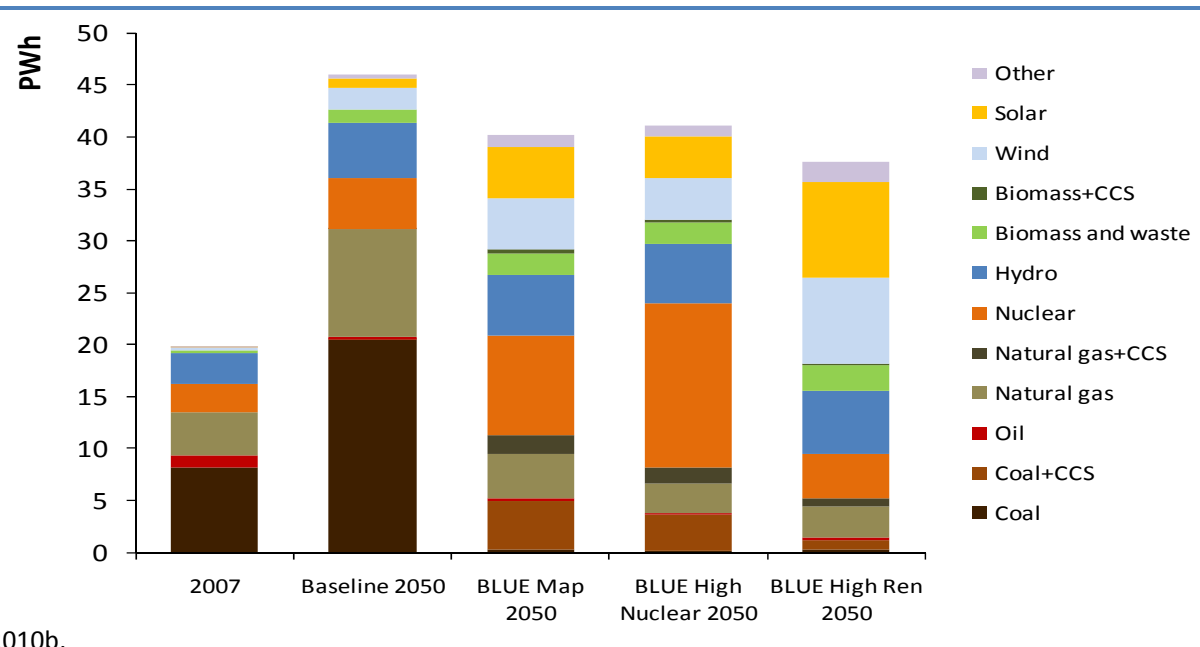

\section{How are cost reductions best achieved?}

These cost reductions are expected to come, in a large part, from an early deployment of these technologies. This is the crux of the longer-term perspective: even if the early deployment of some renewables now has higher costs of immediate emission reductions than other options, this deployment must be undertaken if the cost reductions it drives are key to future large-scale deployment. The early deployment of RE technologies is a cost-effective measure for long-term climate change mitigation, even if it looks too costly when only short-term reductions are considered.

This argument is often challenged on the basis that research and development (R\&D), instead of early deployment, would lead to the cost reductions required for later, large-scale deployment. Indeed, most critics of early mitigation efforts, including those challenging the science of climate change, tend to defer all policy needs to support to R\&D efforts. They argue that if the science confirms the necessity of mitigating climate change, the necessary carbon-lean technologies will be made available (Lomborg, 2001).

Others recognise the need for both carbon policy instruments and government support to R\&D, as they recognise here two distinct market failures. One is climate change, due to the negative externality of GHG emissions: the other is underinvestment of private firms in R\&D activities. This second market failure is due to the fact that firms investing in R\&D activities cannot entirely prevent the diffusion of the knowledge gained through these activities to others, including their competitors. Although such "knowledge spillovers" are considered "positive externalities" (i.e. they make the social value of R\&D greater than its private value), they legitimise the government support to R\&D activities - independently of climate policy.

One interesting example is provided by Fischer and Newell (2008). They have developed a unified framework to assess the six different policy options for reducing GHG emissions and promoting the development and diffusion of renewable energy in the electricity sector. Although the relative cost of individual policies in achieving reductions depends on parameter values and the emissions target, in a numerical application to the US electricity sector, Fischer and Newell state that the ranking (by decreasing efficiencies) is roughly as follows: 1 ) emissions price; 2) emissions performance standards; 3) fossil power tax; 4) renewables share requirement; 5) renewables subsidy; and 6) R\&D subsidy. In a nutshell, they find that "when the ultimate goal is to reduce 
emissions, policies that create incentives for fossil-fuelled generators to reduce emissions intensity, and for consumers to conserve energy, perform better than those that rely on incentives for renewable energy producers alone."

Fischer and Newell note that an optimal portfolio of policies achieves emissions reductions at a significantly lower cost than any single policy:

Page | 12 Given the presence of more than one market failure - an emissions externality and knowledge spillovers - no single policy can correct both simultaneously; each poses different trade-offs. The presence of knowledge spillovers means that separate policy instruments are necessary to optimally correct the climate externality and the externalities for both learning and R\&D. In fact, we find that an optimal portfolio of policies can achieve emissions reductions at a significantly lower cost than any single policy, although the emissions reductions continue to be attributed primarily with the emissions price.

Some specifics of the model used explain this result, which contradicts the cost-effectiveness argument. The model has two periods. There is a knowledge stock, which increases in period 2 as a function of both R\&D expenditures and output of RE technologies in period 1 . The costs of RE generation in period 2 are inversely proportional to the knowledge stock. The model takes into account incomplete appropriation of the benefits from increased knowledge, which justifies R\&D subsidies or RE deployment subsidies or both. In any case, "an emissions price alone, although the least costly of the single policy levers, is significantly more expensive alone than when used in combination with optimal knowledge subsidy policies." The optimal mix has three distinct policy instruments: support to R\&D, a carbon price and RE deployment support.

In this way, Fischer and Newell confirm that the coexistence of several policy instruments does not increase but reduces the costs of mitigating climate change, despite the limited temporal perspective of their research, which explores relatively mild emission reduction objectives.

One set of difficult questions remains: what are the relative weights of $R \& D$ expenditure and learning-by-doing? Which is the most important source of increased knowledge? And, are both similarly appropriable by the firms, or should one consider different spillover ratios for each? According to Fischer and Newell, "if learning is more firm-specific and less likely to spill over, policies subsidising renewables are less appropriate to compensate for knowledge externalities. In contrast, if learning is more difficult to patent to appropriate rents, then renewable subsidies may be relatively more justified" than R\&D support.

A classical perspective tends to describe the technical change as a linear process going from invention to innovation to diffusion (Schumpeter, 1942). A more modern - and possibly more realistic - perspective instead sees technical change as a cyclical process, based on two-way feedbacks between market experiences and technical developments. Not only are market prospects the most vital stimulant of industry R\&D efforts, but more importantly the deployment of technologies in a competitive marketplace is a key source of information on their strengths and weaknesses, and thus on the directions applied R\&D efforts might take. Market development and technology development go hand in hand (IEA, 2003).

This perspective is borne out by lessons from past technological developments, which reveal that the costs of technologies decrease as total unit volume rises. The metric of such change is the progress ratio, defined as the reduction of cost as a consequence of the doubling of cumulative installed technology. This ratio has proven roughly constant for most technologies - although it differs significantly from one technology to another. However, the fact that the progress ratio is usually constant means that technology learning occurs more quickly from market experiences when technologies are new than when they are mature. The same absolute increase in cumulative production has a more dramatic effect at the beginning of a technology's deployment 
than it has later (IEA, 2000). This is why new techniques, although more costly at the outset, may become cost-effective over time if they benefit from sufficient dissemination. So-called learning curves illustrate this phenomenon with straight lines on log-log graphs (Figure 2).

Figure 2: Photovoltaic learning curve 1976-92: linear and log-log representations
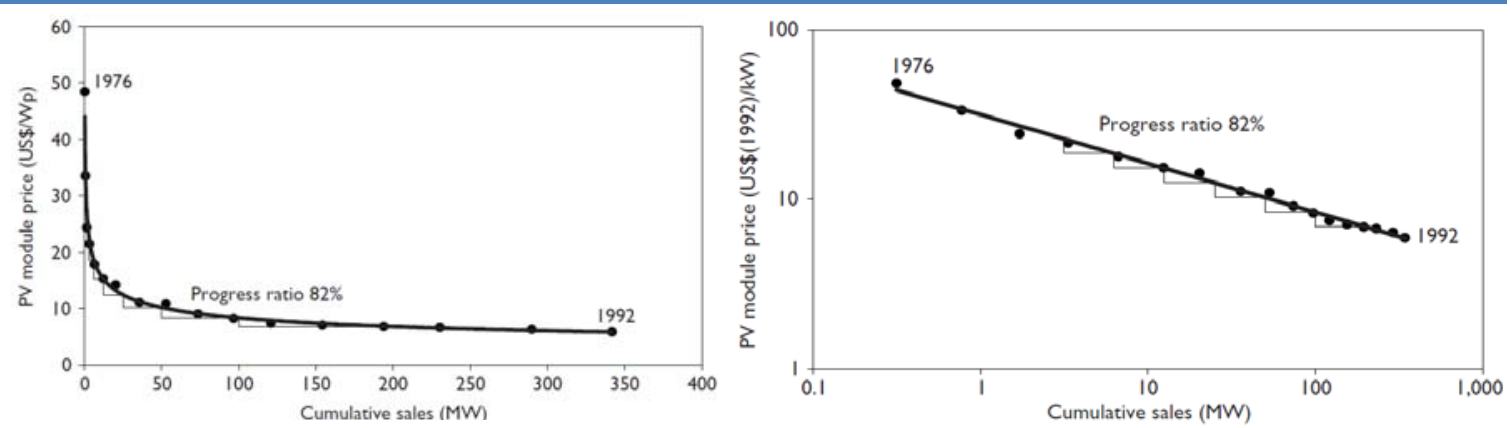

Note: The two figures represent the same learning curve, that of PV modules from 1976 to 1992 . Linear scales are used on the lefthand figure for both sales and prices, while both scales are logarithmic on the right-hand side figure.

Source: IEA, 2000.

Still, it remains difficult to clearly distinguish between the effects of R\&D efforts and those arising from market deployment (Clarke and Weyant, 2003). Learning-curve literature usually lacks a detailed history of R\&D expenditure, while R\&D literature often ignores learning effects. Moreover, the coexistence of increased market shares and decreased costs does not necessarily demonstrate that the former caused the latter. The causality relationship works both ways: when costs decrease, markets increase.

The Energy Technology Perspectives (ETP 2010) publication (IEA, 2010b) extends the analysis far beyond that of Fisher and Newell. It offers a cost-optimisation exercise, which takes into account current and future costs (with a $10 \%$ discount rate) of reducing energy-related $\mathrm{CO}_{2}$ emissions to half their 2005 levels by 2050 . This IEA analysis shows that by 2050, RE technologies should provide $48 \%$ of the global electricity production - and more (57\%) if the discount rate is lowered to $3 \%$. To attain these least-cost solutions, the model progressively includes growing shares of RE technologies in the electricity and energy mixes, including those that are not yet competitive and need support. For most of them, this support is needed in this decade and possibly the next one, beyond the pricing of $\mathrm{CO}_{2}$.

As ETP 2010 states, "It will not be possible to decarbonise the electricity, without strong policy intervention. Today, many low carbon alternatives are considerably more expensive than the incumbent technologies. Governments will need to continue and expand the range of transitional incentives from RD\&D support to market mechanisms to foster technological innovation and move technologies towards market competitiveness. These incentives should be tailored to the maturity of the technology and be decreasing over time. This should be accompanied by policies that close the dirtiest and least efficient plants at the earliest opportunity."

ETP 2010 makes extensive use of the learning-curve theory considered in its broader sense of deployment-led cost reductions. Although the reliability of this theory as a predictive tool cannot be absolute, analyses of actual sources of cost reduction (as in the IEA Technology Roadmaps publications) show that its foundations are solid (Box 1). 
Some recent studies attempt to shed light on the determinants of cost reductions associated with the learning-curve theory. For example, Nemet (2006) studied the cost reductions of electricity from crystalline silicon PV modules from 1975 to 2001, and sought to disaggregate historic cost reductions - of factor 20 during this period - into observable technical factors. He identified three major factors of cost reductions from 1980 to 2001: manufacturing plant size, module efficiency and silicon cost.

From its academic origin (Arrow, 1962), learning-by-doing is sometimes seen in the very narrow sense of "increased workers' productivity" due to experience, other factors remaining constant. Nemet suggests this was a relatively minor factor underlying the drivers of cost reduction. The success of some new entrants was instead due to their capacity to raise capital and take on the risk of large investments. Ten out of the 16 major advances in module efficiency can be traced back to government and university research and development programmes, while the other six were accomplished in companies manufacturing PV cells. Finally, reductions in the cost of purified silicon were a spill-over benefit from manufacturing improvements in the microprocessor industry.

It is interesting to extend the examination of the PV technology beyond the end of the period considered by Nemet. Up to that point, much of the progress in PV growth had been supported through niche markets - in remote places where PV was already the most cost-effective solution. Soon after, large incentive programmes began in Japan and Germany for grid-connected PV modules. In the first years, it seemed that the learning curve theory was proving wrong: PV prices remained higher than expected. Analysts have attributed this to the bottleneck formed by the shortage of appropriate purified silicon and supply market. Since 2008, however, prices have fallen drastically and joined almost exactly the level assigned to their cumulative development by the learning-curve theory (Figure 3).

\section{Figure 3: PV learning curve}

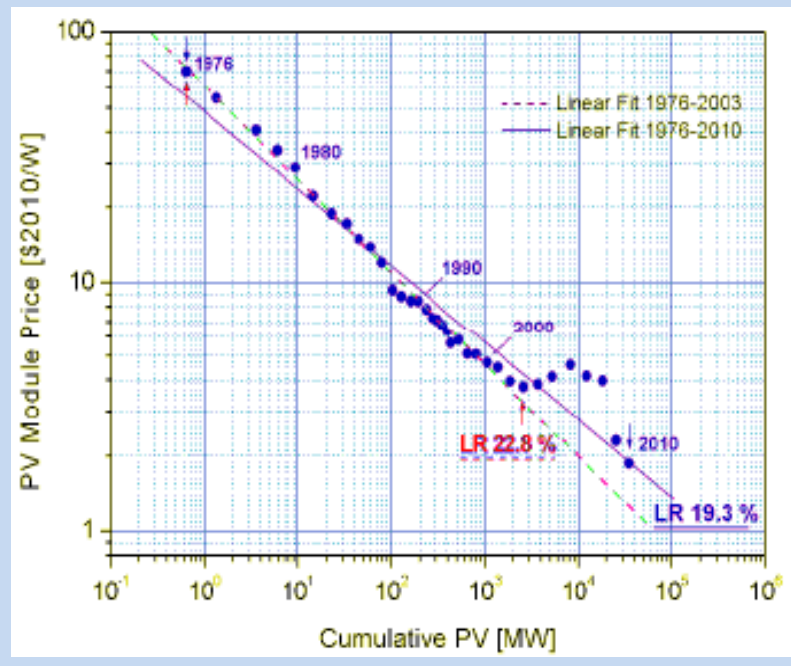

Source: Breyer and Gerlach, 2010.

Increased deployment has thus been, through various channels, the most important driver of cost reductions. Nemet's analysis does not invalidate the policy prescription based on deployment-led cost reductions which is included in IEA ETP projections to 2050. The projections are also based on analyses of the cost reduction potentials to be mobilised in future learning phases, and milestones towards competitiveness in progressively broader electricity markets (see IEA Technology Roadmaps, in particular IEA, 2010c).

Detailed analyses would identify possible limits within the hidden drivers of cost reductions: for example, limits to PV-cell efficiency or to plant size. Resource exhaustion - when good sites get more scarce or remote, or if the proportion of variable sources in electric generation pushes up integration costs - can slow deployment and progress along the learning curve, but would not modify its slope. 
Figure 4: Corporate and public PV R\&D expenses

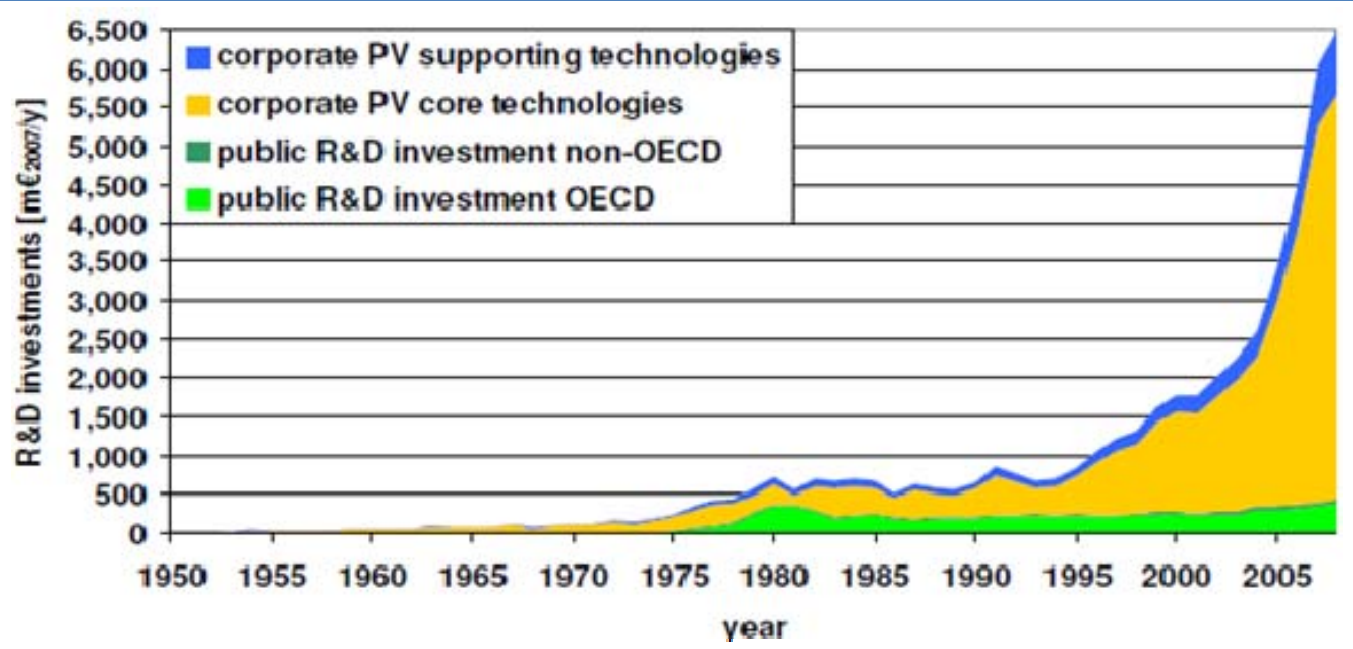

Source: Breyer et al., 2010.

Well-designed incentives for deployment are also effective in fostering research, development and demonstration efforts and innovation; and these can be specifically encouraged by still other instruments, such as the loan-guarantee programme of the American Energy Act of 2005. Recent analyses point to a significant effect of incentives for early deployment on private research and development expenditures in the case of photovoltaics (Figure 4). 


\section{Discussion: locking-in, locking-out}

The somewhat provocative expression "Green serves the dirtiest" designates policies supporting renewable energy deployment as the only culprit of the paradoxical advantage given to fossil fuels which emit higher levels of $\mathrm{CO}_{2}$. The problem, if there is one, arises from the interaction of Page | 16 the two policies. ETS alone would certainly give an advantage to cleaner fossil fuels; RE policies alone would essentially disadvantage all types of fossil fuels.

As noted by several other authors (see the review by Fischer and Preonas, 2010), the addition of an RE policy to an existing ETS is unlikely to lead to additional $\mathrm{CO}_{2}$ emission reductions from the entities covered by the ETS. This does not result from a failure of the RE policy: it is a simple and logical consequence of the very design of the ETS, which is a fixed quantity policy. Things would be different, however, if the policy directly addressing $\mathrm{CO}_{2}$ emissions was a price policy or a hybrid policy. In case of a price policy - say, a carbon tax $-\mathrm{CO}_{2}$ reductions driven by the RE policy could possibly add to the $\mathrm{CO}_{2}$ reductions driven by the carbon tax, depending on the strength of each. In case of a hybrid policy, such as an ETS with a price floor, a reduction of the carbon price resulting from the $\mathrm{RE}$ policy could possibly lead to additional $\mathrm{CO}_{2}$ emission reductions, inasmuch the carbon price were to fall below the level of the price floor.

The remaining question is whether the short-term, relative advantage given to more $\mathrm{CO}_{2}$ intensive generation technology could trigger some detrimental lock-in of such technology, at the expense of efforts to cut emissions.

The feedback process from markets to technical improvements providing increasing returns tends to create "lock-in" and "lock-out" phenomena: it is not (always) because a particular technology is efficient that it is adopted, but (sometimes) because it is adopted that it will become efficient (Arthur, 1989). Technological paths might very much depend on initial conditions. As such, technologies having small short-term advantages may "lock-in" the technical basis of a society into technological choices that may have lesser long-term advantages than technologies that are "locked-out".

The systemic and cumulative nature of technological change leads to clustering effects, or technological interdependence, and possible phenomena of increasing returns: the more a technology is applied, the more it improves and widens its market potential. Change goes in a persistent direction based on an accumulation of past decisions. As noted by Roehrl and Riahi (2000), "technological change can go in multiple directions, but once change is initiated in a particular direction, it becomes increasingly difficult to change its course." To which they rightly add: "research, development and demonstration efforts as well as investment decisions in the energy sector over the next two to three decades are critical in determining which long-term technological options in the energy sector may be opened, or which ones may be foreclosed."

How does this apply to the issue of fuel shifting vs. renewables? Fossil fuel technologies have had a very large global market for more than a century. They can still improve, but marginally. If the combination of $\mathrm{RE}$ and $\mathrm{CO}_{2}$ policies reduces the short-term use of the dirtier fossil fuel technologies less than $\mathrm{CO}_{2}$ policies alone would do, the consequences in technology development for both dirtier and cleaner fossil fuels would be minor. The introduction and deployment of new $\mathrm{RE}$ technologies from a very narrow basis holds the possibility of more considerable progress.

In other words, RE policy instruments will unlock the potential of renewables but will not likely lockin the fossil fuel industry into its dirtier forms. It must be noted in this context, that while shifting from coal to gas in electricity generation does reduce GHG emissions, in climate-friendly scenarios like the 450 Scenario of the WEO 2010 (IEA, 2010a) the global consumption of natural gas decreases after 2020 while renewable energy production continues to expand. In this scenario, the 
contribution of renewable to electricity production reaches 14500 TWh by 2035 (from 3800 TWh in 2008), the contribution of modern renewable to the production of heat increases from $10 \%$ in 2008 to $16 \%$, and the production of biofuels for transportation multiplies sevenfold.

Other possible forms of locking-in deserve greater consideration, in particular with respect to energy efficiency improvements. Some energy efficiency measures need to be undertaken at a given time - for example, when new plants or buildings are designed and built - or risk costing much more at a later stage. Accepting too large an investment in renewable technologies while neglecting timely energy-efficiency programmes clearly runs the risk of locking-in societies' toohigh energy consumption patterns, with detrimental long-term implications for both energy security and climate protection.

The cost-effectiveness argument against RE policies has much less weight when the long term is considered, and does not lead to the conclusion that RE incentives should be abandoned - but it does not vanish. Policies designed to support the deployment of renewable energies must be as cost-effective as possible, and their total costs must remain under control. The WEO 2010 (IEA, 2010a) has assessed the global cumulative cost of support to renewables (i.e. the price paid to renewable energy producers over and above the prevailing market price) at USD 4 trillion from 2010 to 2035 in its New Policy Scenario - of which 63\% for electricity and 37\% for biofuels - and USD 5.2 trillion in its 450 Scenario. Although these numbers are to be seen in proportion to wholesale electricity prices (Figure 5), these are not small sums; creating incentives to support renewable energy's deployment and cost-effectiveness will be further examined in the IEA publication Deploying Renewables (IEA, forthcoming).

Figure 5: Average wholesale electricity prices and renewable support cost by scenario and major region, 2010-35

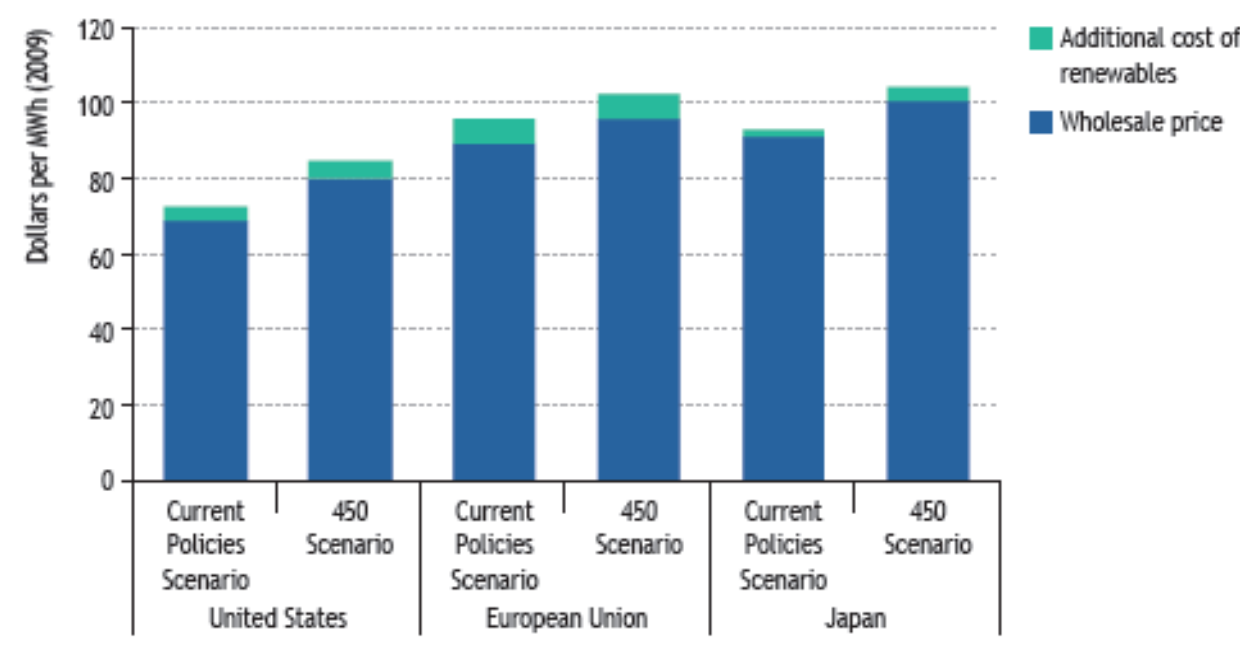

Source: IEA, 2010a.

\section{Other interaction effects}

Another possible aspect of the interaction between $\mathrm{CO}_{2}$ and $\mathrm{RE}$ policies seems to have received very little attention so far. It relates to how both policies transfer wealth from utilities to (deregulated) customers or vice versa.

Several studies show, from either theoretical models or observations from existing electricity markets, that the introduction of a large share of RE electricity tends to reduce the electricity price for deregulated customers (for a review, see Pöyry, 2010). 
This can best be observed with the case of wind power, which has recently become a significant player in some European countries. At about the same time, their electricity markets underwent deregulation. In deregulated markets, the price is set where supply and demand curves meet. The demand for electricity is relatively inelastic - it does not change much with the price. Typically, the supply is made up of various power technologies: wind, hydro, nuclear, combined heat and power plants, coal and natural gas plants, and gas turbines. In a power market, the supply curve is called the "merit order curve" and goes from the least to the most expensive units, taking account only of the marginal variable costs (mostly fuel costs). Utilities bill all kilowatt hours sold on a deregulated spot market, at the price set by the last and most costly unit. Therefore, they get the benefit of so-called infra-marginal rents.

The variable marginal cost of wind is very low, and thus wind power enters near the bottom of the supply curve. This shifts the supply curve to the right (Figure 6) and leads, in general, to lower power spot prices. This so-called merit-order effect is larger in peak demand times, where the merit order curve is especially steep. With more wind into the mix, the size of the rents is reduced, for the benefit of deregulated customers and to the detriment of utilities.

Figure 6: How wind power influences the power spot price at different times of the day

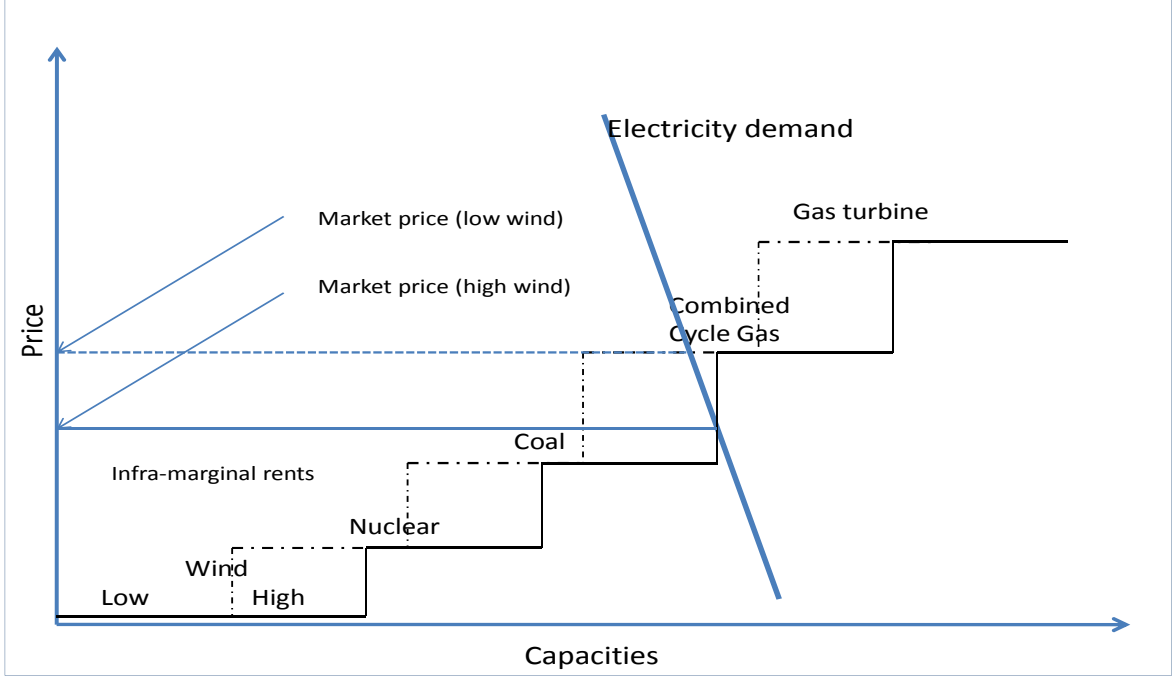

A few empirical analyses have attempted to estimate this merit-order effect. For example, Sensfuß et al. (2008) calculate that the volume of the merit-order effect would have been EUR 5 billion in 2006 in Germany if the entire electricity demand of a single hour was purchased at the corresponding spot market price. Meanwhile, the cost of incentives for renewables in that same year totalled EUR 5.6 billion.

The same authors estimate the value of the kilowatt hour produced by renewables (i.e. the costs avoided by substitution of electricity from other sources) at around EUR 2.5 billion, leaving EUR 3.1 billion as the true extra cost of RE support incentives. Of these, 0.6 billion are directly paid by final consumers, while the remainder EUR2.5 billion are basically paid by utilities through a decrease of their infra-marginal rents due to the merit-order effect. In this way, the merit-order effect transfers wealth from utilities to deregulated customers.

In reality, not all electricity is sold on the spot market in Germany, and bilateral contracts mitigate this result. Furthermore, the lower price paid by deregulated customers does not represent a lower cost for producing electricity. The overall cost of wind kilowatt hours remains higher than some competitors, even if the gap has considerably narrowed in the last decade. Utilities may ultimately find ways to pass part of these costs to customers. 
A more recent study on wind power in Ireland provides even more striking results. Clifford and Clancy (2011), using a detailed model of the all-Island Single Electricity Market, show that the wind generation expected in 2011 will reduce Ireland's wholesale market cost of electricity by around EUR 74 million. This is approximately equivalent to the sum of the Public Service Obligation (financing the feed-in tariff for wind) cost, estimated as EUR 50 million, and the increased "constraint" (or balancing) costs incurred due to wind in 2011. The reduction of Ireland's dependence on fossil fuels and the $\mathrm{CO}_{2}$ emission cuts cost nothing in this case, despite the persistence of the support scheme which ensures recovery of the long-term costs of electricity generation from the wind even when the market prices are low.

It has also been shown that the electricity producers and utilities have enjoyed windfall profits from the implementation of the ETS, because the resulting increase in the marginal electricity prices has increased their infra-marginal rents at the detriment of their deregulated customers. This is also an effect of the merit order (Figure 7). Keppler and Cruciani (2010) have estimated these windfall profits for the utility sector as a whole at more than EUR 19 billion for the first phase of the EU ETS, and state that this phenomenon will only be partially mitigated by the auctioning of emission allowances from 2013 on. From this perspective, the interaction between $\mathrm{RE}$ and $\mathrm{CO}_{2}$ policy instruments, which work in opposite directions in transferring wealth from utilities to industry customers and vice versa, tend to off-set each other's effects, at least in part.

Figure 7: Merit order and electricity price increase with $\mathrm{CO}_{2}$ price

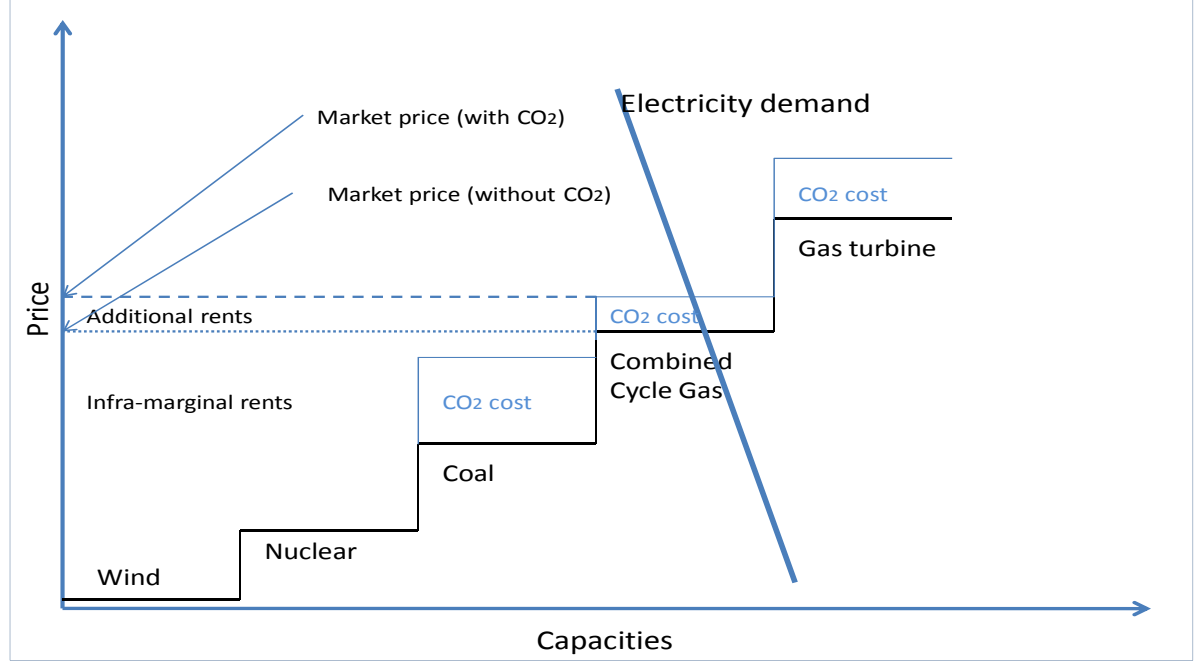

The quantitative assessment of the impacts of the merit-order effect and other interactions needs further research. This assessment will be crucial to determine the real costs of renewable energy incentives for society. 


\section{Conclusion}

The juxtaposition of a $\mathrm{CO}_{2}$ policy instrument of a fixed quantitative form (such as the EU ETS) and of policy instruments specifically promoting the early deployment of RE technologies, may lead to a $\mathrm{CO}_{2}$ price that is lower than it would have been otherwise. It may also raise the overall costs of

Page | 20 achieving the short-term $\mathrm{CO}_{2}$ reductions of the ETS, as this is attained through some costlier emission reductions driven by RE technology deployment. Meanwhile, both policies entail wealth transfers between utilities and deregulated industry customers that work in opposite directions, thereby off-setting each other's effect.

However, as soon as technology improvements are factored in, even for a relatively limited period of time, the optimal portfolio minimising the long-term cost of support policies broadens to at least three instruments: one addressing the $\mathrm{CO}_{2}$ externality directly; one addressing the spillover effects from R\&D efforts; and one addressing the spill-over effects from learning-bydoing. Various other policy instruments might be needed to address non-economic barriers. Looking farther into the future, the prominent role of RE technologies in mitigating climate change becomes more important. Current policies pave the way for making their necessary large-scale deployment affordable, thanks to learning-by-doing processes in the broad sense of the term.

A possible policy recommendation would be to take better account of the interactions among policy instruments. If the RE policy is to be defined first given its longer-term role and strategic importance in addressing climate change, the carbon policy should then be adjusted to take the RE policy into account. This could be done with either relatively more ambitious targets or with a more flexible design incorporating a carbon price floor.

This examination of the interactions between $\mathrm{RE}$ technology deployment and $\mathrm{CO}_{2}$ emission reduction policy instruments also reveals important areas for future investigation. The reduction of infra-marginal rents for utilities resulting from the merit-order effect raises issues relating to future investments in new capacities, as well as research relating to the appropriate calculations of true benefits and costs of renewables in complex electric systems. The true cost of the deployment policy for ratepayers is not the simple sum of the incentives, but rather much less, as renewables progressively reduce the market costs of electricity through the merit-order effect. Finally, how $\mathrm{CO}_{2}$ prices and $\mathrm{RE}$ deployment interact in wealth transfers between various stakeholders, notably electricity customers and utilities, deserves further scrutiny. 


\section{References}

Arrow, K.J. (1962), "The Economic Implications of Learning-by-Doing", Review of Economic Studies, Vol. 29, No. 3, pp. 155-173.

Arthur, W.B. (1989), “Competing Technologies: Increasing Returns and Lock-in by Historical Events", Economic Journal, Vol. 99, No. 394, pp. 116-131.

Böhringer, C. and K.E. Rosendahl (2009), "Green Serves the Dirtiest - On the Interaction Between Black and Green Quotas", Discussion Paper N581, Statistics Norway, Research Department.

Breyer, C., C. Birkner, F. Kersten, A. Gerlach, J.C. Goldschmidt, G. Stryi-Hipp, D.F. Montoro and M. Riede (2010), "Reserch and Development Investments in PV - A Limiting Factor for a Fast PV Diffusion?", Q-Cells, Bitterfeld-Wolfen, Germany.

Breyer, C. and A. Gerlach (2010), "Global Overview on Grid-Parity Event Dynamics", Q-Cells, Bitterfeld-Wolfen, Germany.

Clarke, L.E. and J.P. Weyant (2003), "Modelling Induced Technological Change: An Overview”, in A. Grübler, N. Nakićenović and W.D. Nordhaus (eds.), Technical Change and the Environment, IIASA, Laxenburg, Austria.

Clifford, E. and M. Clancy (2011), "Impacts of Wind Generation on Wholesale Electricity Costs in 2011", SEAl/EirGrid, Ireland.

Fischer, C. and R.G. Newell (2008), "Environmental and Technology Policies for Climate Mitigation", Journal of Environmental Economics and Management, Vol. 55, pp. 143-162.

Fischer, C. and L. Preonas (2010), "Combining Policies for Renewable Energy", Discussion Paper, RFF DP 10-19, Resources for the Future, Washington, D.C.

IEA (International Energy Agency) (2000), Experience Curves for Energy Technology Policy, OECD/IEA, Paris.

IEA (2003), Creating Markets for Energy Technologies, OECD/IEA, Paris.

IEA (2010a), World Energy Outlook 2010, IEA/OECD, Paris.

IEA (2010b), Energy Technology Perspectives 2010, IEA/OECD, Paris.

IEA (2010c), Technology Roadmap: Solar photovoltaic energy, IEA, Paris.

IEA (2011), Deploying Renewables, IEA/OECD, Paris.

IPCC (Intergovernmental Panel on Climate Change) (2007), Climate Change 2007: Synthesis Report, IPCC, Geneva.

Keppler, J.H. and M. Cruciani (2010), "Rents in the Power Sector due to Carbon Trading", Energy Policy, Vol. 38, pp. 4280-4290.

Lomborg, B. (2001), The Sceptical Environmentalist: Measuring the Real State of the World, Cambridge University Press.

Nemet, G.F. (2006), "Beyond the Learning Curve: Factors Influencing Cost Reductions in Photovoltaics", Energy Policy, Vol. 34, pp. 3218-3232.

Pöyry (2010), Wind Energy and Electricity Prices - Exploring the 'Merit Order Effect', the European Wind Energy Association (EWEA), Brussels. 
Roehrl, R.A. and K. Riahi (2000), "Technology Dynamics and Greenhouse Gas Emissions Mitigation: A Cost Assessment", in N. Nakicenovic (ed.), Global Greenhouse Gas Emission Scenarios, a special issue of Technological Forecasting and Social Changes, Vol. 63, Nos. 2-3.

Schumpeter, J. (1942), Capitalism, Socialism and Democracy, Harper, New York.

Sensfuß, F., M. Ragwitz and M. Genoese (2008), "The Merit-Order Effect: A Detailed Analysis of the Price Effect of Renewable Electricity Generation on Spot Market Prices in Germany", Energy Policy, Vol. 36, pp. 3086-3094. 


\section{iea}

\section{International Energy Agency}
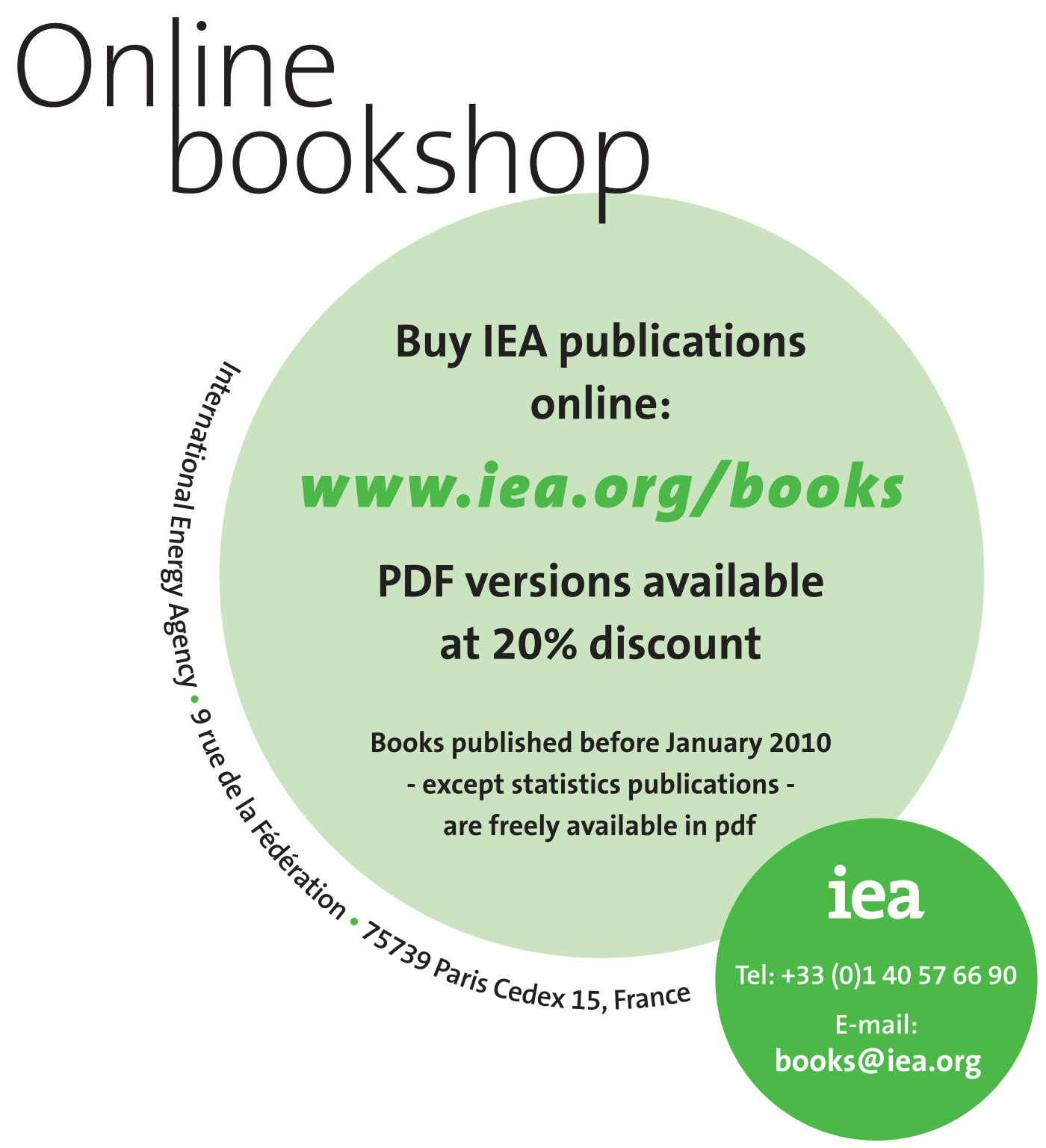
International Energy Agency

9 RUE DE LA FÉdÉRATION 75739 Paris Cedex 15

www.iea.org 